\title{
Effects of abdominal compartment syndrome on gastric emptying time
}

\author{
Balci $C^{1}$, Kaya $E^{2}$, Demirkan $I^{3}$, Sivaci ${ }^{1}$, Ibis $A^{1}{ }^{1}$, Akbulut $G^{4}$, Ela $Y^{1}$ \\ Department of Anesthesiology and Intensive Care, Afyon Kocatepe University Hospital, Turkey. \\ cbalci2001@yahoo.com
}

\begin{abstract}
Introduction: Increase in intra-abdominal pressure may affect gastric emptying time but the precise effect has not been demonstrated. Effects of acute increase of intra-abdominal pressure on gastric emptying time can not be demonstrated in clinical or experimental studies. In this study we aimed to study the effect of increased intra-abdominal pressure on gastric emptying time.

Methods: Six male stray dogs that weighed $20-25 \mathrm{~kg}$ were studied. Following the induction of general anaesthesia, an abdominal catheter was placed and intra-abdominal pressure was raised at a rate of $5 \mathrm{~cm}_{2} \mathrm{O}$ every 10 minutes using intra-abdominal administration of physiologic saline solution until $45 \mathrm{~cm} \mathrm{H}_{2} \mathrm{O}$ pressure was reached. Gastric emptying time was measured scintigraphically at the begining of the study ${ }^{2}\left(\mathrm{IAB} 0 \mathrm{~cm}_{2} \mathrm{O}\right)$ and again four hours later when pressure reached the maximum value (IAP was $45 \mathrm{~cm} \mathrm{H}_{2} \mathrm{O}$ ).

Results: Gastric emptying time for baseline pressure was in average $51.83 \pm 13.16$ whereas for $45 \mathrm{~cm} \mathrm{H}_{2} \mathrm{O}$ pressure it was in average $90.83 \pm 26.96$. This difference was found statistically significant $(p<0.05)$. The differences between baseline values and values after increased intra-abdominal pressurewere statistically significant (Tab. 4, Fig. 1, Ref. 26). Full Text in PDF www.elis.sk.

Key words: abdominal compartment syndromes, scintigraphy, gastric emptying.
\end{abstract}

List of abbreviations: IAP - intraabdominal pressure, GET gastric emptying time, ACS - abdominal compartment syndrome, ECG - electrocardiography, $\mathrm{SpO} 2$ - peripheral oxygen saturation, ARDS - acute respiratory distress syndrome.

Abdominal Compartment Syndrome (ACS) is characterised by respiratory, renal and cardiovascular disturbances due to suddenly raised intraabdominal pressure (IAP), the result of an increase in volume of intra-abdominal or retroperitoneal contents $(1,2)$. The condition is associated with abdominal traumas $(3,4)$ intra-abdominal or retroperitoneal bleeding (5)ascites (6), ruptured abdominal aortic aneurysm $(7,8)$, pneumo-peritoneum (9), pancreatitis (10), after liver transplant (1), or neoplasm (2). Often, intra-abdominal infections lead to peritonitis, intra-abdominal sepsis and are usually fatal if not treated (11-15). Normal IAP values are below 13 $\mathrm{mmHg}(13,14)$; when it exceeds $10 \mathrm{mmHg}$, cardiac output decreases, and over $15 \mathrm{mmHg}$ renal and splanchnic perfusion falls

${ }^{1}$ Department of Anesthesiology and Intensive Care, Afyon Kocatepe University Hospital, Turkey, ${ }^{2}$ Department of Nuclear Medicine, Medical School, Afyon Kocatepe University Hospital, Turkey, ${ }^{3}$ Department of Surgery, Faculty of Veterinary Medicine, Afyon Kocatepe University,Turkey, and ${ }^{4}$ Department of General Surgery, Medical School, Afyon Kocatepe University Hospital, Turkey

Address for correspondence: C. Balci, MD, Kocatepe University School of Medicine, Anaesthesiology Department, Afyonkarahisar, Turkey. Phone: +90.272.2142065, Fax: +90.272.2133066

Acknowledgements: Authors thank to the staff of intensive care units of A yon Kocatepe University, School of Medicine, Departments of Surgery and Anaesthesiology for their kindly contributions. due to mechanical vascular compression. IAP between 20-25 $\mathrm{mmHg}$ increases peak alveolar pressure (12).

Although the current authors advocate that a link between ACS and gastric emtying time (GET) is feasible, no report related to the effect of ACS on GET has been published. Thus, this paper using scintigraphy aims to investigate the possible associations between increased IAP and GET.

\section{Materials and methods}

The study was conducted under the approval of the animal ethical committee, Afyon Kocatepe University, Turkey. Six adult, male, healthy stray dogs that weighed $20-25 \mathrm{~kg}$ were used in the research.

\section{Anaesthesia and monitoring}

After fasting for $12 \mathrm{~h}$, dogs were premedicated with $0.045 \mathrm{mg} /$ $\mathrm{kg}$ atropine sulphate, $1 \mathrm{mg} / \mathrm{kg}$ xylazine hydrochloride and $2 \mathrm{mg}$ / $\mathrm{kg}$ ketamine hydrochloride and ECG, peripheral oxygen saturation $\left(\mathrm{SpO}_{2}\right)$, heart rate and mean arterial pressure were monitored. General anaesthesia was induced using $3 \mathrm{mg} / \mathrm{kg}$ propofol; and muscle relaxation was achieved using $0.6 \mathrm{mg} / \mathrm{kg}$ rocuronyum bromide. Anaesthesia was maintained using 1.0-0.5\% sevoflurane and $50 \% \mathrm{O}_{2}$, and analgesia provided using 3 microgram $/ \mathrm{kg}$ fentanyl as required.

\section{Ventilatory management}

The lungs were ventilated mechanically (Viasys Healthcare, USA) at a compression pressure of $20-25 \mathrm{~cm} \mathrm{H}_{2} \mathrm{O}$, the tidal vol- 
ume was $10 \mathrm{~mL} / \mathrm{kg}$, and the fresh gas flow adjusted to maintain the end-tidal $\mathrm{CO}_{2}$ level at $30-35 \mathrm{mmHg}$ using a Capnomac $\mathrm{CO}_{2}$ monitor (Detax, Helsinki, Finland). Peripheral oxygen saturation was measured by pulse oximetry (Datex) and was kept at $>95 \%$.

\section{Surgery}

The ventral abdomen was prepared for an aseptic surgery in a routine manner. A plastic sterile $5 \mathrm{~mm}$ diameter tube was inserted into the abdomen through a $2 \mathrm{~cm}$ midline incision cranial to the umblicus to avoid any abdominal leakage. A nasogastric tube was introduced into the stomach and its position confirmed by palpation through the abdominal incision. Then, the abdominal incision was closed using purse-ring. A three-way valve was connected to the tip of the naso-gastric tube, one connected to a bag containing normal saline solution, and the other to a linear manometric- $\mathrm{Hg}$ system. Thus, the IAP was measured continuously, and increased gradually. IAP value at the linear manometric-Hg device was increased gradually by $5 \mathrm{~cm} \mathrm{H}_{2} \mathrm{O}$ every 10 mins to reach $45 \mathrm{~cm} \mathrm{H}_{2} \mathrm{O}$. Heart rate, mean arterial pressure, $\mathrm{ECG}$ and $\mathrm{SpO}_{2}$ were monitored (Petas, Turkey). After the study, the abdominal incision was closed routinely, all tubes removed, and the dogs allowed to recover. They were all subsequently placed in a shelter for rehousing.

\section{Scintigraphic method}

A mixture of $500 \mu \mathrm{Ci}$ (18.5 MBq) Technetium 99m-sulphur colloid (Tc99m-SC) in $150 \mathrm{ml}$ of orange juice was administrated through the nasogastric tube. Baseline dynamic images, 30 consecutive frames of $1 \mathrm{~min}$ each, were obtained. GET $\left(\mathrm{T}_{1 / 2}\right)$ was measured by using a time-activity curve. After 4 hours when
IAP reached $45 \mathrm{~cm} \mathrm{H}_{2} \mathrm{O}$ a similar mixture of $10 \mathrm{mCi}$ (370 MBq) Tc99m-SC was given, the nasogastric tube was removed and an identical scintigraphic procedure was repeated.

\section{Statistical analysis}

The data were analysed using paired samples t-test and the significance level was set at $\mathrm{p}<0.05$.

\section{Results}

There was no significant difference between 1, 2, 3 and 4 hours $\mathrm{SPO}_{2}$, heart rate and mean arterial pressure of control group, statistically (Tabs 1, 2 and 3). Before the study (baseline pressure, 0 $\left.\mathrm{cmH}_{2} \mathrm{O}\right)$ and after 4 hour of induced ACS $\left(45 \mathrm{cmH}_{2} \mathrm{O}\right)$ the values of GET are shown in Table 4. Means of baseline and induced pressure values were 51.8 and 90.5 while SDs were 13.2 and 27.0, respectively, and the difference was statistically significant $(\mathrm{p}<0.05)$ (Tab. 4). It was observed that GET values significantly extended in concordance with IAP increase $(p<0.05)$. Scintigraphic image is shown in Figure 1.

\section{Discussion}

Pathophysiology of ACS mainly relies on sudden increase in IAP. Therefore organ damages are propotionaly caused by values of IAP (16-18). Generally pressures at $20 \mathrm{mmHg}$ or over should be closely monitored. It was reported that pressures exceeding 25 $\mathrm{mmHg}$ require abdominal decompression due to severe systemic physiological effects (19-21). There was no difference between

Tab. 1. Data of study group; Control, 1., 2., 3., and 4. hours peripheral oxygen saturation $\left(\mathrm{SPO}_{2}\right)$ values.

\begin{tabular}{|c|c|c|c|c|c|c|}
\hline Dogs & $\mathrm{SPO}_{2}$ Control & $\mathrm{SPO}_{2} 1$ & $\mathrm{SPO}_{2} 2$ & $\mathrm{SPO}_{2} 3$ & $\mathrm{SPO}_{2} 4$ & $\mathrm{p}$ \\
\hline 1 & $97.66 \pm 0.51$ & $96.66 \pm 0.50$ & $96.65 \pm 0.52$ & $95.60 \pm 0.62$ & $96.60 \pm 0.66$ & $\mathrm{p}>0.05$ \\
\hline 2 & $97.66 \pm 0.51$ & $96.59 \pm 0.55$ & $95.61 \pm 0.60$ & $96.60 \pm 0.66$ & $95.60 \pm 0.62$ & $\mathrm{p}>0.05$ \\
\hline 3 & $97.66 \pm 0.51$ & $95.61 \pm 0.60$ & $96.59 \pm 0.55$ & $95.60 \pm 0.62$ & $96.61 \pm 0.65$ & $\mathrm{p}>0.05$ \\
\hline 4 & $97.66 \pm 0.51$ & $96.60 \pm 0.65$ & $96.61 \pm 0.63$ & $96.60 \pm 0.62$ & $97.60 \pm 0.64$ & $\mathrm{p}>0.05$ \\
\hline 5 & $97.66 \pm 0.51$ & $95.61 \pm 0.60$ & $96.60 \pm 0.66$ & $95.60 \pm 0.62$ & $96.61 \pm 0.65$ & $\mathrm{p}>0.05$ \\
\hline 6 & $97.66 \pm 0.51$ & $96.59 \pm 0.55$ & $95.60 \pm 0.62$ & $96.61 \pm 0.65$ & $96.61 \pm 0.65$ & $\mathrm{p}>0.05$ \\
\hline
\end{tabular}

Tab. 2. 1, 2, 3 and 4 hours values of study group's heart rates (HR).

\begin{tabular}{|c|c|c|c|c|c|c|}
\hline Dogs & HR Control & HR 1 & HR 2 & HR 3 & HR 4 & $\mathrm{p}$ \\
\hline 1 & $179.16 \pm 3.65$ & $170.10 \pm 2.65$ & $171.15 \pm 2.60$ & $172.15 \pm 3.65$ & $174.16 \pm 3.55$ & $\mathrm{p}>0.05$ \\
\hline 2 & $178.11 \pm 4.65$ & $174.14 \pm 3.55$ & $172.12 \pm 3.45$ & $175.12 \pm 3.55$ & $171.14 \pm 3.55$ & $\mathrm{p}>0.05$ \\
\hline 3 & $175.10 \pm 2.65$ & $173.11 \pm 2.65$ & $170.16 \pm 2.75$ & $171.16 \pm 3.75$ & $173.10 \pm 2.61$ & $\mathrm{p}>0.05$ \\
\hline 4 & $181.15 \pm 3.60$ & $179.16 \pm 3.65$ & $175.26 \pm 3.85$ & $176.15 \pm 3.85$ & $178.16 \pm 3.65$ & $\mathrm{p}>0.05$ \\
\hline 5 & $178.14 \pm 3.61$ & $176.26 \pm 3.65$ & $177.36 \pm 3.75$ & $177.16 \pm 3.65$ & $177.16 \pm 3.65$ & $\mathrm{p}>0.05$ \\
\hline 6 & $180.11 \pm 3.60$ & $179.15 \pm 3.65$ & $178.15 \pm 3.75$ & $177.15 \pm 3.45$ & $178.18 \pm 3.85$ & $\mathrm{p}>0.05$ \\
\hline
\end{tabular}

Tab. 3. Data of study group; $1,2,3$ and 4 hours mean arterial pressure (MAP).

\begin{tabular}{|c|c|c|c|c|c|c|}
\hline Dogs & MAP Controle & MAP 1 & MAP 2 & MAP 3 & MAP 4 & $\mathrm{p}$ \\
\hline 1 & $110.08 \pm 2.55$ & $107.66 \pm 3.56$ & $106.58 \pm 2.66$ & $108.88 \pm 3.66$ & $109.88 \pm 2.56$ & $\mathrm{p}>0.05$ \\
\hline 2 & $111.18 \pm 2.65$ & $108.88 \pm 3.56$ & $107.58 \pm 2.45$ & $109.78 \pm 3.56$ & $107.68 \pm 2.76$ & $\mathrm{p}>0.05$ \\
\hline 3 & $99.55 \pm 1.67$ & $98.78 \pm 1.76$ & $99.88 \pm 1.77$ & $99.88 \pm 1.57$ & $98.98 \pm 1.46$ & $\mathrm{p}>0.05$ \\
\hline 4 & $105.68 \pm 1.76$ & $99.65 \pm 3.53$ & $98.88 \pm 1.54$ & $99.66 \pm 1.66$ & $98.68 \pm 1.25$ & $\mathrm{p}>0.05$ \\
\hline 5 & $97.68 \pm 1.56$ & $96.58 \pm 1.56$ & $97.64 \pm 1.35$ & $96.65 \pm 1.15$ & $97.65 \pm 1.55$ & $\mathrm{p}>0.05$ \\
\hline 6 & $100.54 \pm 1.75$ & $98.48 \pm 0.86$ & $97.78 \pm 0.56$ & $97.68 \pm 0.59$ & $97.76 \pm 0.96$ & $\mathrm{p}>0.05$ \\
\hline
\end{tabular}


Tab. 4. GET mean value at baseline pressures and $45 \mathrm{mmHg}$, and comparison.

\begin{tabular}{lccc}
\hline & $\begin{array}{c}\text { Baseline } \\
\text { (IAP-0 mmHg) } \\
\text { T1/2 Time (min) }\end{array}$ & $\begin{array}{c}\text { Under Increased } \\
\text { Abdominal Pressure } \\
\text { (IAP-45 mmHg) } \\
\text { T1/2 Time (min) }\end{array}$ & p \\
\hline Mean Value GET & $51.83 \pm 13.16$ & $90.83 \pm 26.96$ & 0.007 \\
\hline
\end{tabular}

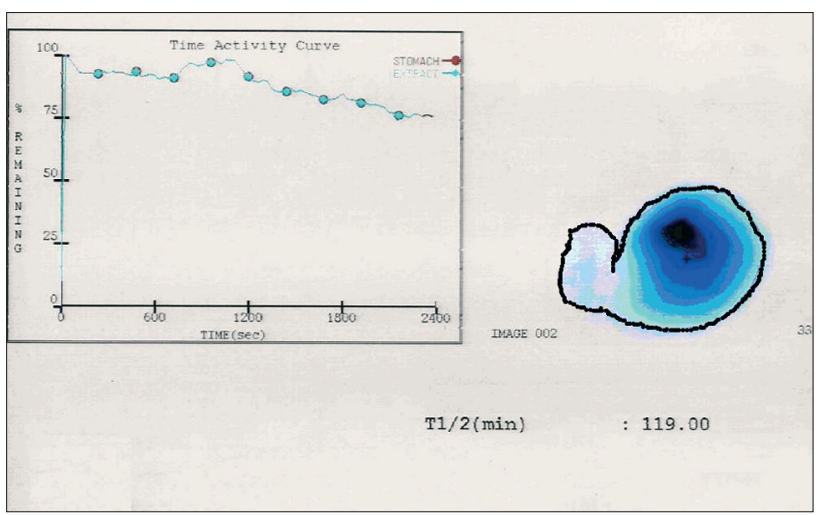

Fig. 1. Region of interest and real time activity curve under $45 \mathrm{mmHg}$ intraabdominal pressure.

subjects's hemodynamic data at the end of the study. Because of entubation and ventilation of the subjects we decided that there were no negative effects on hemodynamic data.

It is not clear yet how GET is effected and what occurs. No reports have been published on the determination of effects of IAP on GET. Moreover pressures effecting GET have not been defined and not demonstrated by any imaging techniques $(22,23)$. The closest study was the measurement of GET in patients who underwent peritoneal dialysis (24). However, in this work, longer GETs were determined despite of the emptied peritoneal cavity. Parameters and GET here were independed from the IAP (24).

Observation on the presence of reflux during increases in IAP may provide a valuable approach to the lung pathologies associated with ACS. Since the minimal abdominal decompression pressure in humans has been accepted as $35 \mathrm{cmH}_{2} \mathrm{O}$, in this study we preferred $45 \mathrm{cmH}_{2} \mathrm{O}$ (exceeding the minimal abdominal decompression pressure) to evaluate GET.At the end of the study, at 45 $\mathrm{cmH}_{2} \mathrm{O}$ IAP, there was a statistically significant difference in GET when compared to baseline pressure $\left(0 \mathrm{cmH}_{2} \mathrm{O}\right)$. As a result, the use of drugs that delay GET and providing positions to patients to prevent pulmonary aspiration in critical care units should be carefully considered.

Pathological changes due to increased pressure may contribute to extended GET and pulmonary aspiration that developes secondarily in relation to reflux of the stomach content.

Further studies are needed to set a light on whether ARDS is a result of sepsis or develops in association with complication of reflux causing sepsis or worsen the sepsis status. The possibility of the aspiration of stomach contents should not be neglected especially in critical care patients despite the intubation (it is also known that secretions accumulate around the intubation tube cuff may be associated with lung infection) $(25,26,27)$.
Clinical importance of extended GET may be attributable to pulmonary aspiration due to reflux. Generally in critical care units there were a little pulmonary aspirations. The main source of the aspirations were oral and nasal secretions. The oral and nasal secretions were accumulated posterior of the cuff in the patients who were entubatedendotracheally. Cuff of the tube can block the pulmonary aspiration but it can notblock minimal pulmonary aspirations and can be a source of nosocomial infections frequently. Gastric reflux canoccur in the patients who are fedby nasogastric tube. Gastric reflux increases the amount of pulmonary aspirations with inosculating intraoral secretions. In intensive care units for protecting the patients from gastric reflux the patients heads must be positioned at 30 degrees and the feeding tube must be placed at the lower part of the stomach and frequent intraoral aspiration must be done.

Deterioration of lung function may increase the severity of hypoxia and acidosis due to imbalance of oxygenation. In our study, we only investigated the GET not the aspiration, therefore future work is required to show detailed features of hispathology and scintigraphy of pulmonary aspiration.

In conclusion, patients with respiratory disorders and pulmonary pathologies undergoing anaesthesia should be closely monitored because of the possible association between IAP and GET. As a result GET can be expected when IAP increases and preventive precautions must be introduced to prevent gastric reflux and pulmonary aspiration in patients with diagnosis of ACSwhoare specially followed at intensive care units..

\section{References}

1. Malbrain ML, Chiumello D, Pelosi P, Wilmer A, Brienza N, Malcangi $\mathbf{V}$ et al. Prevalence of intra-abdominal hypertension in critically ill patients: A multicenter epidemiological study. Intensive Care Med 2004; 30: 822-829.

2. Bloomfield GL, Dalton JM, Sugerman HJ, Ridings PC, DeMaria EJ, Bullock R. Treatment of increasing intracranial pressure secondary to the acute abdominal compartment sydrome in a patient with combined abdominal and head trauma. J Trauma 1995; 39: 1168-1170.

3. Richards WO, Scovill W, Shin B, Reed W. Acute renal failure associated with increased intra-abdominal pressure. Ann Surg 1983; 183-187.

4. Jacques T, Lee R. Improvement of renal function after relief of raised intra-abdominal pressure due to traumatic retroperitoneal haematoma. Anaesth Int Care 1988; 16: 478-482.

5. Barnes GE, Laine GA, Giam PY, Smith EE, Granger HJ. Cardiovascular responses to elevation of intra-abdominal hydrostatic pressure. Am J Physiol 1985; 248: 208-213.

6. Fietsam R Jr, Villalba M, Glover JL, Clark K. Intra-abdominal compartment syndrome as a complicaiton of ruptured abdominal aortic aneurysm repair. Am Surg 1989; 55: 396-402.

7. Kron IL, Harman PK, Nolan SP. The measurement of intra-abdominal pressure as a criterion for abdominal re-exploration. Ann Surg 1984; 199: $28-30$.

8. Safran DB, Orlando R. Physiologic effects of pneumoperitoneum. Am J Surg 1994; 167: 281-286. 
9. Eddy VA, Key SO, Morris JA Jr. Abdominal compartmet syndrome: etiology, detection, and management. J Tenn Med Assoc 1994; 55-67.

10. Shelly MP, Robinson AA, Hesford JW, Park GR. Haemodynamic effects following surgical release of increased intra-abdominal pressure. Br J Anaesth 1987;59: 800-805.

11. Celoria G, Steingrub J, Dawson JA, Teres D. Oligouria from high intra-abdominal pressure secondary to ovarian mass. Crit Care Med 1987; 15: 78-79.

12. Schein M, Wittmann DH, Aprahamian CC,Condon RE. The abdominal compartment syndrome: The physiological and clinical consequences of elevated intra-abdominal pressure. J Am Coll Surg 1995; 180 : $745-753$

13. Nathens AB, Boulanger BR. The abdominal compartment syndrome. Curr Opin Crit Care 1998; 4: 116-120.

14. Eddy V, Nunn C, Morris JA Jr. Abdominal compartment syndrome. The Nashville experience. Surg Clin North Am 1997; 77: 801-812.

15. Malbrain ML, Wyffels E, Wilmer AP, Frans E, Daelemans R. Effects of raised intra-abdominal pressure (IAP) and subsequent abdominal decompression on cardiovascular and renal function in medical ICU patients. In Abstractbook of the 7th World Congress of Intensive Care Medicine. Ottawa, Canada, 1997; 75.

16. Moore FA, Sauaia A, Moore EE, Haenel JB, Burch JM, Lezotte DC. Postinjury multiple organ failure: A bi-modal phenomenon. J Trauma 1996; 40: 501-511.

17. Ivatury RR, Porter JM, Simon RJ, Islam S, John R, Stahl WM. Intraabdominal hypertension after life-threatening penetrating abdominal trauma: prophylaxis, incidence, and clinical relevance to gastric mucosal pH and abdominal compartment syndrome. J Trauma 1998; 44: 1016-1023.
18. Burch JM, Moore EE, Moore FA, Franciose R. The abdominal compartment syndrome. Surg Clin North Am 1996; 76: 833-842.

19. Ertel W, Oberholzer A, Platz A, Stocker R, Trentz O. Incidence and clinical pattern of the abdominal compartment syndrome after "damage control" laparotomy in 311 patients with severe abdominal and/or pelvic trauma. Crit Care Med 2000; 28: 1747-1753.

20. Meldrum DR, Moore FA, Moore EE, Franciose RJ, Sauaia A, Burch JM. Prospective characterization and selective management of the abdominal compartment syndrome. Am J Surg 1997; 174: 667-673.

21. Mariani G, Boni G, Barreca M, Bellini M, Fattori B, AlSharif A. Radionuclide gastroesophageal motor studies. J Nucl Med 2004; 45 : 1004-1008.

22. Feinle C, Kunz P, Boesiger P, Fried M, Schwizer W. Scintigraphic validation of a magnetic resonance imaging method to study gastric emptying of a solid meal in humans Gut 1999; 44: 106-111.

23. Van V, Schoonjans RS, Struijk DG, Verbanck JJ, Vanholder RC, Van B, et al. Influence of dialysate on gastric emptying time in peritoneal dialysis patients. Perit Dial Int 2002; 22: 32-38.

24. Cardoso TC, Lopes LM, Carneiro AH. A case-control study on risk factors for early-onset respiratory tract infection in patients admitted in ICU. BMC Pulm Med 2007; 21: 7-12.

25. Carrilho CM, Grion CM, Bonametti AM, Medeiros EA, Matsuo T. Multivariate analysis of the factors associated with the risk of pneumonia in intensive care units. Braz J Infect Dis 2007;11: 339-344.

26. Hyllienmark P, Gårdlund B, Persson JO, Ekdahl K. Nosocomial pneumonia in the ICU: a prospective cohort study. Scand J Infect Dis 2007; 39: 676-682. 